\title{
A SEMÂNTICA OPERATÓRIA DE "FALSO"
}

\author{
The operative semantics of "falso"
}

\author{
Albano Dalla PRIA ${ }^{75}$
}

Resumo | A lógica não leva em conta, na formalização dos seus raciocínios, a especificidade das línguas naturais. Aplicados à descrição de certas expressões das línguas, tais como 'atestado de óbito falso', os raciocínios da lógica são colocados em xeque. É implícito dos raciocínios lógicos o conceito aristotélico de "classe" ou de espaço fechado, ou se está dentro ou se está fora do espaço. Porque presume a significação construída, esse raciocínio impede a observação do termo atestado de óbito como um gesto de construção de significação. Através do método que é próprio da "Teoria das Operações Predicativas e Enunciativas" (CULIOLI, 1990, 1999a, 1999b), porque articula o material verbal (as línguas) com a prática do seu manuseio (atividade de linguagem) dentro de um espaço topológico ou de uma topologia de domínio aberto, propusemos observar a contribuição de FALSO para o gesto de construção de atestado de óbito. Por fim, concluímos que FALSO é marca da dúvida (modalidade) e do bloqueio (alteridade) à construção do termo atestado de óbito.

Palavras-chave | Adjetivo. Significação. Operações.

\begin{abstract}
The formalization of logical reasoning does not consider the specificity of natural languages. Applied to the description of certain expressions of natural languages, such as 'atestado de óbito falso', the logical reasoning fails. It is implicit that logical reasoning is based on the Aristotelian concept of "class" or closed space; one is within or outside the space. Because this reasoning assumes meaning as constructed, it prevents the observation of the term atestado de óbito as a gesture of meaning construction. Through the method that is proper to the "Theory of Predicative and Enunciative Operations" (CULIOLI, 1990, 1999a, 1999b), as it articulates the verbal material (the languages) with the practice of its manipulation (language activity) within a topological space or an open topology, we propose to observe the contribution of FALSO to the constructing gesture of atestado de óbito. Finally, we conclude that FALSO is a mark of doubt (modality) and of blocking (otherness) to the construction of atestado de óbito.
\end{abstract}

Keywords $\mid$ Adjective. Signification. Operations.

75 Pria. UNEMAT. Endereço eletrônico: adallapria@gmail.com. ORCID ID: https://orcid.org/0000-00027033-3041 
- | A semântica operatória de "falso"

\section{Introdução}

Na lógica proposicional, se eu chamo alguma $\operatorname{cois}^{76}$ de 'atestado de óbito'77, é porque alguma coisa é um atestado de óbito que existe como tal. Uma expressão do tipo 'atestado de óbito falso' coloca em xeque esse raciocínio descritivo. Ela vai contra os princípios da lógica, porque afirma dois estados de coisa que seriam, em princípio, incompatíveis, quais sejam o de que alguma coisa é e não é ela mesma ao mesmo tempo. Isso porque, do ponto de vista lógico, alguma coisa é aquilo que é, segundo o princípio da identidade (A é A), e não pode ser outra coisa diferente dela mesma, segundo o princípio da não-contradição (A é A e não-A). Com efeito, o terceiro termo, isto é, que alguma coisa seja ela mesma e o deixe de ser ao mesmo tempo (A é A ou A é não-A), no escopo de uma mesma proposição, está excluído dos princípios lógicos.

A lógica assume o ponto de vista representacionalista da significação. Desse ponto de vista, as línguas são meios expressivos cuja finalidade é tão somente a de veicular conteúdos prontos da realidade abstrata (conteúdos de pensamento ou proposições) para a realidade físico-cultural (enunciados), sem passar por nenhum tipo de ajustamento, seja no plano da expressão seja no plano do conteúdo.

A especificidade das línguas não é levada em conta na formalização dos raciocínios lógicos. Por isso, enquanto metalinguagem explicativa do funcionamento das línguas, esses raciocínios marginalizam sequências que, na prática de linguagem, não são menos significativas do que outras tantas sequências logicamente válidas. Tal é o caso de 'atestado de óbito falso'.

Dada a dificuldade de se construir um sistema lógico de representação que dê conta de descrever adequadamente o funcionamento linguístico de 'atestado de óbito falso', tomamos uma posição, sustentada pelo programa de trabalho da "Teoria das Operações Predicativas e Enunciativas" (CULIOLI, 1990, 1999a, 1999b), qual seja, a de construir um sistema homogêneo de representação metalinguística que dê conta de apreender não só os valores mais estáveis do nome 'atestado de óbito', semelhantes àqueles que a lógica busca descrever, mas também a gama de valores deformáveis, dentre os quais 'atestado de óbito falso', a que se pode ter acesso, através de manipulações teoricamente controladas da invariante (CULIOLI, 1990) de funcionamento de atestado de óbito dentro de um espaço referenciável ${ }^{78}$ aberto - porém centrado -, chamado Domínio Nocional.

\footnotetext{
76 O termo em construção é representado sempre pelo itálico.

77 As denotações são representadas sempre entre aspas simples.

78 Trata-se de um espaço topológico que organiza um conjunto de ocorrências da noção em relação a um centro atrator ou centro organizador de ocorrências da noção.
} 
O conceito de "Domínio Nocional"79 refere um espaço topológico ou uma topologia de domínio aberto (CULIOLI, 1999a). Essa concepção geométrica do espaço se contrapõe ao conceito aristotélico de classe ou de espaço fechado. Aristóteles compreendia o mundo como uma totalidade geométrica não topológica, ou se está dentro ou se está fora do espaço, e nada mais. A ciência moderna tem explicado (ou descrito) a realidade através um conjunto restrito de categorias segundo o conceito aristotélico de classe. Ficam excluídos do tratamento científico os objetos que não se reduzem à homogeneidade que o conceito de classe lhes impõe. Na passagem das representações abstratas para as representações linguísticas, as primeiras, enquanto formalizáveis das últimas, podem resultar algo diverso daquilo que se tinha por formalizar. O "centro atrator"80 (CULIOLI, 1990, p. 97) serve de ponto de convergência (transindividual) da identidade (invariante) de forma. Com efeito, o centro visa controlar a construção do hiato que rupturas de base podem produzir.

O método que é próprio à apreensão da linguagem através das línguas naturais não se reduz a um conjunto de valores axiomáticos de base - eles próprios deduzidos de uma teoria implícita - que, aplicados à descrição dos fenômenos, acabam por lhes imprimir valores originários da teoria como se lhes fossem inerentes. A concepção de teoria que articula o material verbal (as línguas) com a prática do seu manuseio (atividade de linguagem) dispõe de um método que implica, primeiro, que nos apropriemos, através de processos indutivos, da invariante que regula uma série de enunciados em família parafrástica; segundo, que simulemos, através de processos hipotético-dedutivos, gestos controlados de deslocamento de posições mais ou menos fixas dentro de um espaço referenciável. A metodologia de análise do funcionamento de $\mathrm{FALSO}^{81}$ implica, portanto, a apreensão do movimento (vaivém) que caminha do funcionamento de FALSO na organização de estados provisórios de conhecimento (que antecipam ações sobre o exterior) até uma posição estabilizada de FALSO num espaço referencial exterior (que determina posições mais ou menos fixas na superfície das línguas), e vice-versa. Em suma, o método se traduz pelo movimento do empírico ao formal (CULIOLI, 1990), e não pela estaticidade - que marcou a Linguística da segunda metade do século XX - resultante da polarização entre esses dois extremos.

\footnotetext{
79 Sua finalidade é estruturar classes de ocorrências da noção em um espaço topológico que compreende um interior (lugar do atrator), um exterior, uma fronteira e um complementar (CULIOLI, 1990, p. 70). O interior é um espaço aberto (CULIOLI, 1990, p. 70) orientado por um processo de identificação (um Xi é identificado com um $\mathrm{Xj}_{\mathrm{j}}$ com um centro atrator cujos valores compreendem ponderações desde o 'verdadeiramente $p^{\text {' }}$ (identificação com o interior) até o 'verdadeiramente não- $p^{\prime}$ (não-identificação com o interior), passando pelo 'não verdadeiramente $p^{\prime}$ e o 'não verdadeiramente $n \tilde{a} o-p^{\prime}$ ', na região de fronteira.
}

80 É um polo de referência para a construção de representações e condição para a regulação intersubjetiva (CULIOLI, 1999b, p. 11).

$81 \mathrm{O}$ termo cujo funcionamento é objeto deste trabalho sempre representaremos em maiúsculas. 
Ao final dos anos 80 do século passado, Culioli (1990, p. 10) ${ }^{82}$ já vislumbrava o que depois se confirmou sobre a evolução da linguística após a II Guerra Mundial. Em razão de se ter fixado o objeto da linguística como sendo um sistema idealizado construído a partir de línguas específicas, principalmente as europeias, o teórico já entrevia uma tendência à polarização entre, de um lado, domínios teóricos e, de outro lado, domínios aplicados. A polarização só veio a agravar

[...] o problema entre, de um lado, uma pesquisa que se aplica às línguas na sua especificidade e às configurações que lhes são próprias, de outro lado, uma pesquisa que se aplica à atividade de linguagem (qual seja a atividade de representação, referenciação e de regulação, apreendida na sua gênese [...] (CULIOLI, 1990, p. 10) $)^{83}$.

Foge aos propósitos deste trabalho a construção de um modelo fixo, que exclui ou apaga dos observáveis a dimensão subjetiva (atividade) da linguagem (variação experiencial e perceptiva). As manipulações que fazemos dos enunciados, além de teoricamente controladas, estão orientadas para a construção de um modelo plástico e maleável dos processos de apreensão do

[...] agenciamento de marcadores que são, eles mesmos, traços de operações, quer dizer, são a materialização de fenômenos mentais aos quais não temos acesso e dos quais, enquanto linguistas, só podemos dar uma representação metalinguística, isto é, abstrata (CULIOLI, 2002, p. 27, grifos do autor) ${ }^{84}$.

Nosso objetivo é contribuir para uma maior compreensão:

1. dos processos de determinação das noções semânticas, ou "quase-signos" (REZENDE, 2000), que implicam, de um lado, a introdução de alguma coisa (um objeto simbólico não qualquer) referenciável, provisoriamente chamada 'atestado de óbito', no espaço referenciável e, de outro lado, a determinação propriamente dita, através de avaliações qualitativas - que tem FALSO como marcador - sobre a identidade de alguma coisa em relação à representação visada de atestado de óbito nesse último espaço;

82 A publicação original é de 1987.

83 No original: "le problème de l'articulation entre, d'une côté, une recherche qui portait sur les langues dans leur spécificité et avec leur configuration propre, d'une autre côté une recherche qui portait sur l'activité de langage (qu'il s'agisse d'activité de représentation, de référenciation, de régulation, appréhendée dans sa genèse [...]" (CULIOLI, 1990, p. 10).

84 No original: “c'est un agencement de marqueurs, qui sont eux-mêmes la trace d'opérations, c'est-à-dire, que c'est la matérialisation de phénomènes mentaux auxquels nous n'avons pas accès, et dont nous ne pouvons, nous linguistes, que donner une représentation métalinguistique, c'est-à-dire, abstraite" (CULIOLI, 2002, p. 27 , grifos do autor). 
2. dos processos sucessivos de ajustamentos entre sistemas de representação não homogêneos.

Com efeito, esperamos nos aproximar dos valores operatórios que, em situação prática de construção de significação, são, de fato, observáveis das formas linguísticas, em geral, e, em particular, da sequência 'atestado de óbito falso'.

\section{A predicação lógica e os dilemas de gênese}

Do ponto de vista lógico, o conteúdo independe das línguas para significar. Delas depende apenas para ser veiculado. A veiculação não implica ajustamentos porque a realidade física e a realidade abstrata são tomadas pela lógica numa relação de continuidade que se confunde com a mesmice. O mundo e o pensamento se recobrem perfeitamente, quer dizer, o mundo é "transparente" ao pensamento, e vice-versa. Essa relação garantiria a estabilidade do conteúdo, não obstante a variação experiencial e linguística, que é própria à atividade linguageira.

Para a lógica, o mais importante é a comprovação da validade de um raciocínio. A lógica não pretende ser uma forma de ação sobre o mundo, sobre os referentes. Por isso, os raciocínios lógicos passam da realidade física para a realidade abstrata, e viceversa, dentro de uma realidade orgânica, abstraindo de qualquer tipo de ajustamento, conforme já o dissemos acima no contexto da veiculação dos conteúdos. Qual seria, então, a razão do trabalho dos sujeitos em relacionar as unidades?

O sujeito da lógica se assemelha a um autômato, na construção de sentenças declarativas que possam ser avaliadas em termos de verdadeiro e falso quanto aos estados-de-coisas que descrevem. O trabalho do sujeito da lógica é axiomático, tomado por evidente, e calçado na instrumentação normativa do pensamento, sob a justificativa da necessidade de se "disciplinar" o pensamento ${ }^{85}$. Esse sujeito, por um lado, confundese com a realidade abstrata e dela se apaga; por outro lado, confunde-se com a realidade físico-cultural e dela também se apaga. É um sujeito que está em todo tempo-lugar e em tempo-lugar algum. Esse sujeito se converte em puro pensamento ou pura introspecção (solipsismo). Esse sujeito não precisa equilibrar representações interiorizadas com as representações dos outros sujeitos.

85 Os fins justificam-se em si mesmos como forma de se aproximar da verdade e/ou se afastar do erro. 
- | A semântica operatória de "falso"

\section{A atividade epilinguística e o trabalho do linguista}

Em síntese, o termo "epilinguismo" refere o trabalho do sujeito para posicionar (répérer) raciocínios subjacentes através de "formas que marcam e constroem sua presença, formas que traçam a atividade dos sujeitos (sob a ótica que essas formas Ihes conferem)" (VOGÜÉ; FRANCKEL; PAILLARD, 2011, p. 11, grifos dos autores) num espaço referencial homogêneo. As línguas naturais são performativas. Se os sujeitos relacionam entidades, é porque intuem a possibilidade de transformá-las, se não no plano físico-cultural ou afetivo, pelo menos no plano simbólico.

As formas de superfície se constituem interpretáveis em razão dos raciocínios (teoria) que lhes são subjacentes. Os raciocínios só são acessíveis através das formas, que são vestígios das operações que organizam, localizam e controlam a representação dentro de um evento em processo de construção. Se, por um lado, sabe-se, por hipótese, da existência de invariantes cuja presença na língua é marcada por formas, por outro lado, é preciso construir caminhos de acesso, quer dizer, formalizações, a esse saber. Nesse sentido, o acesso à teoria (invariante) implica um saber-fazer do linguista que, assim como no artesanato, implica o próprio ato de fabricação (DUCARD, 2006).

Do ponto de vista da linguagem definida como atividade de representação, referenciação e regulação (CULIOLI, 1990), o trabalho do linguista deve se voltar à manipulação de enunciados e à formalização dos observáveis. Esse trabalho visa simular o investimento da ação subjetiva, "que Culioli chama de força assertiva" (DUCARD, 2009, p. 65, grifo do autor), em projetos de representação que se deslocam sob ângulos perceptivos variados. Ressalte-se, portanto, que a ação subjetiva é constitutiva dos observáveis, quer dizer, os observáveis são objetos que articulam ação subjetiva e formalização de ângulos perceptivos através das línguas. A experiência subjetiva é constitutiva das línguas ${ }^{86}$, e vice-versa.

Numa abordagem dinâmica - que acreditamos ser a nossa - dos fenômenos linguísticos, a linguagem, enquanto a prática de construção de significação numa língua dada, impede-nos de defender os fundamentos da abordagem estática, quais sejam (a) a existência de um plano abstrato de relações intersubjetivas estabilizadas e (b) a existência de um sistema de relações determinadas entre forma e conteúdo que não comporta deformações. Também não podemos sustentar que existam "algumas entidades de língua que sejam determinadas e outras que sejam menos determinadas" (REZENDE, 2000, p. 15).

86 De modo diverso do nosso, a lógica toma as línguas como instrumentos do pensamento, que permanece incólume a qualquer organização das unidades de língua em sequências singulares. 
O funcionamento de FALSO de que trataremos aqui não se confunde com a descrição da totalidade do fenômeno que se encerra em si mesma. Nossos observáveis famílias de enunciados em relação parafrástica - não se confundem com os conceitos de dado e de fenômeno enquanto objetos estabilizados. Porque esses conceitos abstraem da ação subjetiva e da variação de ângulos perceptivos subjacentes (invariante), cujas marcas são constitutivas das línguas. Esses dois conceitos costumam referir objetos que perderam sua gênese na "prática, seja de interação verbal dos falantes de uma língua, seja de interação dos falantes com o meio ambiente" (REZENDE, 2000, p. 12).

A linguística culioliana reabilita a gênese (perdida) da variação nas línguas e assume uma posição diante dela: a gênese de toda a variação é experiencial e subjetiva, e não formal ou processual. A variação diz respeito aos modos de perceber e representar o mundo por sistemas não homogêneos (transindividuais) que, em princípio, não dialogam, razão essa do trabalho dos sujeitos para se fazer dialogar.

\section{Processos enunciativos de funcionamento de FALSO}

Trabalhamos com contexto explícito das intuições ${ }^{87}$ que estão sustentando processos de formalização de enunciados em família parafrástica, ao mesmo tempo em que vamos construindo um sistema metalinguístico de representação que dê conta de descrever o formal que a linguagem é, isto é, como mecanismo de forma que dá sustentação não só a caminhos que levam a bom termo, porque constroem representação, mas também trajetórias que ficam a meio caminho ou que não se transformam e - de um certo ponto de vista que não é o nosso - não constroem representação. Para tanto, consideremos o diálogo abaixo:

(1) Você pagou a indenização a Pedro pela morte da sua esposa?

(2) Não! De jeito nenhum.

(3) Por quê?

(4) Pedro me entregou um atestado de óbito falso.

Assumimos um valor semântico interpretável não qualquer de atestado de óbito falso, que só pode ser apreendido através de ocorrências particulares, tais como no diálogo acima formalizado. Nossa unidade de análise é o enunciado. Em outros termos,

87 "Se as ciências desconfiaram oficialmente da analogia, praticaram-na clandestinamente. Muitos cientistas utilizam o raciocínio por analogia para construir tipologias, elaborar homologias ou mesmo induzir leis gerais, mas os manuais apagam o rastro do caminho mental subjetivo, assim como o enobrecimento apaga os rastros da sua extração vulgar" (MORAN, 2012, p. 156). 
- | A semântica operatória de "falso"

Culioli atribui ao enunciado um duplo estatuto - teórico e material. É uma unidade empírica de observação porquanto constituída de materialidade e, por isso, o dado mais diretamente observável ao linguista; é uma entidade teórica porquanto é definido como agenciamento de marcadores de operações da atividade de linguagem. Dessa perspectiva, em sua atividade de análise, o linguista parte de dados imediatos e caminha em direção à formulação de dados teorizados (famílias parafrásticas) que lhe fornecem subsídio para retornar ao empírico (PRIA, 2013, p. 42).

O processo constitutivo do enunciado compreende um conjunto de relações imbricadas. Em síntese, são relações de natureza primitiva, predicativa e enunciativa. Por ocasião da análise do enunciado (4) será possível observar o funcionamento dessas relações na sua constituição. Aqui, procuramos contemplá-las em três momentos, privilegiando uma relação em cada momento. Não se pretende esgotar - como se isso fosse possível as relações em tela. Ainda que tenhamos optado por tratá-las em separado, as relações se sobrepõem, como se poderá perceber do texto.

O primeiro momento ou SITO (= Situação zero) trata da instanciação de um esquema formal por noções semânticas e da organização de domínios nocionais; o segundo, SIT1, trata da organização de posições que visam dar existência aos termos do enunciado; o terceiro, SIT2, trata dos ajustamentos das situações anteriores diante de um contexto discursivo.

Todo enunciado é um evento que nasce de uma relação semântica entre domínios nocionais e aponta para uma certa direção de sentido, um lugar onde as propriedades dos termos estão cultural e historicamente adequadas. Para fins de manipulação do enunciado e explicitação da relação semântica que aqui se afigura, comecemos por colocar uma situação zero, doravante SIT0, e um esquema de léxis.

SIT0: determinação da orientação semântica.

A léxis é um esquema formal de três lugares $\left\langle\xi_{0}, \xi_{1}, \pi>\right.$ que prevê uma variável para o operador $\pi$ e duas variáveis, $\xi_{0}$ e $\xi_{1}$, para os argumentos da predicação. Os espaços formais da léxis são instanciados por noções semânticas e, do ponto de vista cognitivo, asseguram a estruturação do conteúdo de pensamento ou conteúdo proposicional. Trabalharemos com a seguinte léxis: <Pedro entregar atestado-de-óbito $>$. 
A "intuição criadora"88 (DUCARD, 2006) projeta, para uma eventual situação enunciativa $\left(\text { Sit }^{*}\right)^{89}$, que sejam ratificadas as propriedades ${ }^{90}$ dos termos da léxis, tais como estão relativamente estabilizadas na cultura: Pedro sendo aquele que tem a propriedade de entregar, dentre outras coisas, um atestado de óbito, e atestado de óbito sendo alguma coisa que pode ser entregue por alguém, dentre os quais, Pedro. O enunciado (5) traduz esses valores. Observa-se do enunciado a ausência de marcas que remetam a um possível bloqueio à construção dos termos, algo que se traduz por um enunciado como (6).

(5) Pedro me entregou um atestado de óbito por ocasião da morte da sua esposa.

(6) Pedro não me entregou um atestado de óbito porque estava desconsolado com a morte de sua esposa.

A confirmação das propriedades dos termos, numa eventual situação enunciativa (Sit*), pode resultar na construção quer do ENTREGADOR $(<(\quad)$ entregar atestado-deóbito $>$ ) quer do ENTREGADO (<Pedro entregar ( ) $>$ ) quer de ambos os termos, através do predicado entregar. Os termos que vierem a se construir, numa eventual situação enunciativa (Sit*), darão conta de quão adequados estão os termos em relação às noções que os quer "encanar" (REZENDE, 2000). Os termos em construção, no nosso enunciado de partida, são Pedro e atestado de óbito.

Colocadas em relação, as noções semânticas da léxis esboçam não só uma orientação semântica, "uma grosseira direção de sentido" (REZENDE, 2011, p. 707), quer dizer, uma relação mais ou menos adequada entre os termos e as noções semânticas que lhes quer encarnar, mas também um "projeto de existência" (REZENDE, 2000) da representação visada (7), provisoriamente representada pelo termo atestado de óbito.

(7) Alguma coisa entregue por Pedro.

Com efeito, esse gesto que visa trazer à existência alguma coisa ainda pouco determinada cuja determinação maior é ter sido introduzida num espaço referenciável, através da associação da ocorrência de alguma coisa a um termo do léxico, é o primeiro passo na direção da sua construção nesse espaço. Por certo, não é um acaso a escolha do

88 No original: intuition créatrice (DUCARD, 2006, p. 16).

$89 \mathrm{O}$ asterisco sempre representa um valor hipotético.

90 Propriedades que estão relativamente estabilizadas nas culturas, tais como, humano, animado, adulto, infantil, inanimado, individuável, massivo, processo finalizado, iniciador, acidental, e assim por diante (CULIOLI, 1999a, p. 100). 
termo, resulta da analogia de alguma coisa com ocorrências da noção /atestado de óbito/91, conhecidas do enunciador. São operações de qualificação ulteriores que poderão validar a adequação na escolha do termo. No enunciado (8), as marcas de modalidade assertiva e de aspecto perfectivo (ausência de obstáculo) do contexto encaixante contribuem para essa confirmação. Outro enunciado pode colocar a dúvida sobre a adequação, tal é o caso de (9).

(8) Pedro me entregou um atestado de óbito, é pena que sua esposa esteja morta.

(9) Pedro nos trouxe um atestado de óbito sem valor algum, será mesmo que sua esposa está morta?

SIT1: determinação da direção dos termos.

A imersão da léxis num espaço referencial qualquer (abstrato ou físico-cultural), impõe que os termos sejam ordenados numa sequência linear. A ordenação, no entanto, esboça enunciáveis cuja existência dos termos pode não ser conhecida dos sujeitos num espaço referenciável. O objetivo da relação predicativa é a construção dessa existência dos enunciáveis. Vejamos as duas glosas a seguir:

(10) [Há] Um atestado de óbito [que] foi entregue por Pedro [nosso conhecido] para alguém.

(11) Pedro [nosso conhecido] entregou um atestado de óbito [há alguma coisa] para alguém.

Enquanto (11) está construindo a existência de um ENTREGÁVEL cujo ENTREGADOR é conhecido dos sujeitos, em (10) está sendo construída a existência do ENTREGADOR cujo ENTREGÁVEL ainda é pouco conhecido dos sujeitos.

As posições dos termos refletem, em alguma medida, as posições dos sujeitos no espaço referenciável. Em (10), glosamos a posição do enunciador (S0) sobre co-enunciador (S2), antes mesmo que S0 se tenha feito locutor (S1), numa situação enunciativa. S0 sabe que S2 não sabe alguma coisa de S0 sobre Pedro. Colocar o enunciado no plano do dizível implica eliminar essa diferença. Aquilo que S0 sabe de S2 se converte numa posição de S0 em relação a S2. S0 se sobrepõe a S2 no espaço referenciável. Que é a projeção da imagem do enunciador (S0) sobre o co-enunciador no enunciado (10). O enunciador (S0) está

\footnotetext{
91 Os termos entre barras oblíquas sempre representam noções. A noção é uma entidade de caráter híbrido que, na atividade de linguagem, recupera toda a atividade simbólica (CULIOLI, 1990, p. 50). Trata-se de um sistema complexo que estrutura propriedades físico-culturais construídas a partir da nossa interação com o mundo (CULIOLI, 1990). Por isso, a noção ultrapassa o linguístico. Ela está na origem da categorização do mundo e na representação de propriedades físico-culturais por uma dada língua e por uma dada cultura. Do ponto de vista linguístico, só pode ser apreendida através de suas ocorrências em eventos enunciativos.
} 
sustentando a posição de alguém (um S com o qual S0 se identifica) que supõe ser o coenunciador (S2). Tal suposição se traduz pelo marcador de localização há. Trata-se de um operador que visa introduzir alguma coisa no universo de discurso para que predicações ulteriores possam se efetivar sobre alguma coisa. Esse valor se traduz pela seguinte glosa (12). Com esse gesto, S0 constrói a existência fictícia de um enunciável.

(12) Há alguma coisa, falemos dela.

Em (11), também glosamos a posição do enunciador (S0) sobre o co-enunciador (S2), antes mesmo que S0 se tenha feito locutor (S1). S0 sabe que S2 sabe alguma coisa de S0 sobre Pedro. Aquilo que S0 sabe de S2 converte-se, mais uma vez, numa posição de $S 0$ em relação a $S 2$, qual seja a de que S0 e S2 ocupam a mesma posição no espaço referenciável. Desse ponto de vista, uma eventual diferença (S2 não sabe alguma coisa de S0 sobre Pedro) não se coloca ou fica em segundo plano, pois, vindo a se colocar, pode construir algum bloqueio à trajetória de determinação de um ENTREGADOR. Para tanto, não se questiona a identidade de alguma coisa enquanto ENTREGADO. Ao nível das relações predicativas essa diferença é pano de fundo. Presume-se de (11) um certo modo de existir do termo atestado de óbito. Com efeito, (11) retoma uma ocorrência de alguma coisa cujo modo de existir ainda pode ser questionado ao nível das relações enunciativas quer para ser colocado em dúvida, como em (13), quer para ser (14). S0 constrói a existência do enunciável sob um gesto que abstrai dessas posições.

(13) O Pedro então nos entregou um atestado de óbito? Conta outra. De onde ele tirou um atestado de óbito?

(14) Foi emitido com rapidez o atestado de óbito que Pedro nos entregou [um atestado de óbito]

A estrutura predicativa, embora seja um modo particular de apreensão do mundo e resulte da apropriação da realidade psico-física e cultural por um sujeito particular, configura uma construção de tal modo generalizada, porque distende a tal ponto o tempo, o espaço e o mundo (sujeitos), que compreende o conteúdo proposicional, sempre igual em si mesmo, onde toda diferença se apaga.

SIT2: determinação da estabilidade intersubjetiva.

Ainda que, através da ordenação, a relação predicativa esboce posições, ela o faz no sentido da sua exclusão. Se essas posições podem ser retomadas na relação enunciativa, entendemos que se deva ao fato de a intersubjetividade já estar colocada enquanto projeto - mas ainda não construída - ao nível das relações predicativas. A intersubjetividade é um projeto, e não está dada para o enunciado. Por certo, a intersubjetividade ou as posições intersubjetivas - do modo como as entendemos - são construtos da atividade de linguagem. Estamos nos apoiando "na hipótese fundadora de que a atividade de 
linguagem é produto de uma atividade simbólica por gestos" (DUCARD, 2009, p. 68) de apropriação de relações predicativas, mas não só, que se esboçam numa certa direção, mas que nem sempre se constroem como tal. A heterogeneidade do discurso, assim como a sua transcendência, não pode ser tomada nem como anterior nem como exterior às formas que permitem dela dizer, "ela lhes é inerente" (VOGÜÉ; FRANCKEL; PAILLARD, 2011, p. 11).

A adequação nocional (SIT0) construída sobre uma eventual situação enunciativa (SIT1) é uma disposição do enunciador (SO) que pode vir a se constituir locutor (S1*). A possibilidade de deslocamentos está na base da apropriação dessa invariante. Toda invariante não-ainda formalizada em relação a uma situação singular (Sit), através de formas interpretáveis de uma língua dada, é suscetível de deslocamentos dentro de um espaço referenciável. Por isso, há sempre o risco de se dizer outra coisa, na passagem das representações abstratas para as representações linguísticas. Nessa passagem, é o centro atrator que assegura possíveis reorganizações do conteúdo proposicional frente às posições que estavam colocadas enquanto projeto na relação predicativa, mas que, na relação enunciativa, tendem a se constituir como posições de fato. É de princípio a não coincidência dos modos de ser do conteúdo de pensamento ou da proposição. A continuidade é resultado do investimento do sujeito, e não um fundamento da atividade significante. A intuição de estabilidade enquanto mesmice deve-se, muitas das vezes, às aproximações (analogia com a memória enunciativa ou com projeções enunciativas) que uma disposição atual convoca para a apropriação de formas interpretáveis, caminho de acesso que são a uma "ambiguidade fundamental"92 (CULIOLI, 1999a, p. 160). O trabalho do sujeito para passar de uma disposição à outra interessa-nos mais do que as descrições que podem ser feitas das aproximações em si.

FALSO é marca do trabalho do sujeito, uma disposição de S0, para passar de um modo de ser de alguma coisa, esboçado em SIT0 e projetado em SIT1, para um modo de ser outro-o-mesmo que a SIT2 Ihe assegura. O mesmo em razão da identidade de forma que é localizada em relação a uma situação particular (Sit) e outro em razão da reorganização nocional que essa localização implica. A passagem de uma situação eventual (Sit*) para uma situação particular (Sit) não é sem consequência. FALSO é, antes de tudo, marca da modalidade da dúvida sobre a posição dos sujeitos da Sit a respeito de alguma coisa. FALSO é marca de alteridade (dissociação) enunciativa. Em SIT2, S0 está dissociado da posição de um eventual locutor $\left(S 1^{*}\right)$, mas não da disposição de S0, projetada em SITI, para uma eventual situação enunciativa (Sit*).

No nosso enunciado de partida, é a alteridade enquanto o mesmo, mas em outro tempo-espaço, que coloca em dúvida a possibilidade de que alguma coisa se construa como uma ocorrência da noção /atestado de óbito/. FALSO está em consonância com 
(13) e em contraposição a (14). FALSO é a marca da dúvida de S1, excluída de SIT1, quanto à construção de alguma coisa como uma ocorrência da noção /atestado de óbito/. A negação da existência de um atestado de óbito que existe como tal é um pano de fundo que não se resolve com FALSO. FALSO marca o bloqueio à trajetória de construção de atestado de óbito que se esboçou em SIT0 e cuja existência se projetou SIT1. Esse bloqueio dá margem a todo tipo de especulação - que não é nosso objetivo fomentar - sobre a trajetória da representação a partir de Sit.

Em SIT2, S1 força a volta - como se isso fosse possível ou sem consequência - à situação zero, passando pela situação um, como uma trajetória possível. A volta, ou melhor, a sua tentativa, não é sem consequência para o enunciado. FALSO é a marca dessa consequência do movimento (trabalho) de construção da representação no contexto do enunciado, e não só para o fragmento atestado de óbito.

\section{Considerações finais}

Depois de ter passado em revista um conjunto extenso de gramáticas brasileiras de 11 diferentes autores - todos eles apoiados no conceito aristotélico de classe - uma pesquisadora concluiu: "Todos eles apontam que o adjetivo indica 'qualidade(s)'" (NEVES, 2011, p. 17). No avesso da tradição gramatical, observamos, na prática de construção de significação, que FALSO é marca da dúvida (modalidade) e do bloqueio (alteridade) à construção do termo atestado de óbito, na trajetória da construção do enunciado.

A lógica já apostou na derivação de subtipos como alternativa ao tratamento extensional (ILARI, 1993), que "falha" na descrição de adjetivos como FALSO. Uma razão plausível para a "falha" é o bloqueio do qual FALSO é o marcador, na construção do nome e na construção da classe de predicados que poderiam ser descritos pelo nome. Como a lógica trabalha com fragmentos de enunciado, fica difícil perceber tanto o movimento construtor da representação quanto os obstáculos que pode vir a encontrar. Buscamos aqui explicitar que esse movimento é muito maior do que o conteúdo que uma construção possa encapsular.

\section{Referências}

CULIOLI, A. Pour une linguistique de l'énonciation: opérations et représentations. Paris: Ophrys, 1990.

CULIOLI, A. Pour une linguistique de l'énonciation: formalisation et opérations de repérage. Paris: Ophrys, 1999a. 
- | A semântica operatória de "falso"

CULIOLI, A. Pour une linguistique de l'énonciation: domaine notionnel. Paris: Ophrys, 1999b.

CULIOLI, A. Variations sur la linguistique. Entretiens avec Frédéric Fau préface et notes de Michel Viel. Paris: Klincksiek, 2002.

DUCARD, D. O grafo do gesto mental na teoria enunciativa de A. Culioli. Tradução de Consuelo Vallandro Barbo. Letras de Hoje, Porto Alegre, v. 44, n. 1, p. 64-71, 2009.

DUCARD, D. Seuils, passages, sauts. In: DUCARD, D.; NORMARD, C. (Orgs.). Antoine Culioli: un homme dans le langage. Paris: Ophrys, 2006. p. 13-18.

ILARI, R. Alguns problemas semânticos na análise dos adjetivos. Cadernos de Estudos Linguísticos, Campinas, v. 24, p. 41-45, 1993.

MORAN, E. O método 3: conhecimento do conhecimento. Tradução de Juremir Machado da Silva. 4. ed. Porto Alegre: Sulina, 2012.

NEVES, M. H de M. Uma amostra do tratamento concedido às classes de palavras na tradição gramatical do português. Confluência, Rio de Janeiro, v. 39, p. 11-28, 2011.

PRIA, A. D. O diálogo, a significação e a enunciação na articulação da linguagem com as línguas naturais. In: PRIA, A. D.; MOTTA, A. L. A. R. da; RENZO, A. D.; MORALIS, E. G. Linguagem, escrita e tecnologia. Campinas: Pontes, 2013. p. 37-50.

REZENDE, L. M. A indeterminação da linguagem e o conceito de atividade no ensino de língua materna. Estudos linguísticos, São Paulo, v. 40, n. 2, p. 707-714, 2011.

REZENDE, L. M. Léxico e gramática: aproximação de problemas linguísticos com educacionais. 2000. 320 f. Tese (Livre docência) - Faculdade de Ciências e Letras, Universidade Estadual Paulista, Araraquara, 2000.

VOGÜÉ, S.; FRANCKEL, J.-J.; PAILLARD, D. Prefácio. In: VOGÜÉ, S.; FRANCKEL. J-J.; PAILLARD, D. (Orgs.) Linguagem e enunciação: representação, referenciação e regulação. Tradução de Marcia Romero e Milenne Biasotto. São Paulo: Contexto, 2011. p. 9-13. 
COMO CITAR ESTE ARTIGO: PRIA, Albano Dalla. Semântica operatória de falso. Revista do GEL, v. 15, n. 2, p. 132-146, 2018. Disponível em: https://revistadogel.gel.org.br/

DOI: $\underline{\text { http://dx.doi.org/10.21165/gel.v15i2.2066 }}$

Submetido em: 15/11/2017 | Aceito em: 08/10/2018 